\title{
A study on industry route design
}

\author{
Xinxi Jiang \\ Professor of Business School, Jiangxi Normal University, Nanchang, Jiangxi, China \\ Yichao Zeng \& Yitian Xie \\ Postgraduate of School of Intercultural Studies, Jiangxi Normal University, Nanchang, Jiangxi, China
}

\begin{abstract}
In the China's time background that in order to encourage people to start their own business and to make innovations, this article explores specific situation in industry planning from the microscopic point of view. It states industry route design from the perspective of practical industry development, and redefines the industry factors. Consider the cask principle as the selection benchmark of core industry, it reckons that industry structure, industry scale, industry quality, industry culture and industry benefit are the main selection factors (industry factors) of industry route design and these factors must be taken into account when designing the industry route. In addition, if core industry is chosen properly, it will inevitably induce an interrelated and complementary industrial cluster and bring a good developmental prospect of regional economy. The structure, scale, quality, culture and benefit of core industry are the key points which can't be ignored.
\end{abstract}

Keywords: Industry route design; Industry factors; Selection of core industry

\section{INTRODUCTION}

Premier Li Keqiang put forward the slogan that "To encourage people to start their own businesses and to make innovations" in Davos Forum 2015, China will continue to encourage the public to start businesses vigorously. But at present, most industry planning theories are based on macroscopic point of view rather than the perspective of industry's actual development. Therefore it needs a microscopic theory to guide the public businesses, namely the industry route design. The important content of industry route design is the choice of industry development direction. And industry structure, industry scale, industry quality (sustainability), industry culture and industry benefit are the main selection factors (industry factors) of industry route design. These industry factors must be taken into account when designing the industry route. The theory of comparative advantage in economic theory relies on industry route design to make specific choice when it is in the practice of economic operation. In other words, industry route design has also an important task that is to give the comparative advantages of industry factors into full play, and develop the industry which has comparative advantage.

\section{REFERENCE REVIEW}

Industry planning is to generally arrange and program the layout of industry development and the adjustment of industrial structure. The Basic theories of industry planning mainly includes: development theory, industrial structure theory, leading industry theory and the theory of areal division of labor, comparative advantage theory, globalization theory, industrial cluster theory and the theories of unbalanced development, such as location theory, central place theory, growth pole theory, point axis development theory, gradient shift theory as well as some related theories of competitive industry such as high and new technology industries, etc.. The existing researches about industry planning theories and methods also proved that the industry planning possesses the above mentioned basic theories: Jun Zou in the research of urban system planning in the new period, points out its economic and industrial development theories mainly is various sorts of "developing stage theories" and "industrial structure theories", economic spatial theories is mainly the "growth pole theories" and "point axis development theories", etc.; Yuming Wang et al. also regards "globalization, industrial clusters, industrial transfer 
and theory of areal division of labor" as the basic theory of overall planning of city industrial layout. In the analysis of the concept planning theory and method, Chaolin $\mathrm{Gu}$ et al. points out that "reorganization, transfer of industrial structure and the choice of competitive industry" is the key point of the industrial development strategy, the theoretical foundation mainly includes "industrial structure theories", "gradient shift theories", "leading industry theories" and "theory of comparative advantage". In addition, many scholars treat "location theories", "point axis development theories", "growth pole theories" as the basic theories of city industrial layout.

Most of the fundamental theories of industry planning are relatively macroscopic, long-acting and backward, the applicable scope of the above mentioned theories are too general and long-term. But when it comes to provide short and medium term practical scheme for specific city, the guidance role seems not big. In our country's industry planning, regional coordination theory and empirical study is not much, implementation is not enough, area control theory only involves city control, and urban system control mainly aims at some aspect of one area and lacks integrality and systematicness.

Therefore, based on the existing theories, this article states industry route design from the perspective of practical industry development, redefines the industry factors, and considers the cask principle as the selection benchmark of core industry. The cask principle in the western economics believes that a wooden cask which consists of a number of battens, whose maximum volume depends on the shortest batten instead of the longest one. Whether the core industry can be correctly selected, the key point is depends on the reasonable choice of structure, scale, quality, culture, and benefit. If one of them is not taken into consideration, it may greatly influence the full play of the utility of core industry.

\section{THE BASIC CONTENT OF INDUSTRY FACTORS}

Industry structure means the proportion which business resources (human resources, finance, material, information, time, relationships, and space) are used in the process of industry operation (the proportion of dynamic structure). Although there is fungibility between business resources, the lack of business resources may lead to the reorganization of industry structure (or the technological innovation which contraposes the missing resource).

Industry scale means the quantitative relationships of utilized business resources and the quantitative relationship between products' production and consumption. The larger scale means the more quantity. On the other hand, industry scale is related to the space-time concept of industry operation, that is, the density (or frequency) of industry operation at one space-time. The larger scale means the bigger density (or more frequency).

Industry quality means the sustainability of industrial growth, namely, the formation, development, stability, and recession of industrial life process. Industrial lifecycle have an important impact not only on contemporary society, economy and culture, but also on the society, economy and culture of next generation. After the industry of previous generation declining, it still remains its cultural identities when the next generation industry forms, and generates irreversible accumulation in resource allocation and market targeting etc.

Industry culture means the social consciousness formed in the process of industry operation, such as institution culture, management culture, business philosophy and industrial population's attitude to industry operation. Industry culture is the fundamental basis of forming industrial added value. The more profound cultural identity will gain the greater added value of the culture. People will follow the industry more deeply at the same time.

Industry benefit means the industry's contribution to society, economy and culture how to make impact on the welfare of industrial population, regeneration of business resources, as well as means the degree of environmental improvement. The benchmark of industry benefit is the sum of social, economic and cultural benefit, ecological benefit and environmental benefit. The harmony between industry and human, nature and industry, and industry and industry should become the standard system of industry benefit. (see Table 1)

\section{THE SELECTION OF CORE INDUSTRY}

The technological group which is composed of core technology and its associated matching technologies can support or induce the formation of core industry. Whether core industry has advancement depends on a large extent on the innovation and advancement of core technology and its associated matching technologies, but also selected industry culture needs to represent the developing direction of advanced culture.

\subsection{The structure selection of core industry}

The structure of core industry is selected according to the amount of business resources and the principle of sustainable development. To a certain degree, combinatorial factors of structure have substitutional relation, which depends on the demand of industry scale for structure. In addition, combinatorial factors of structure are classified into two types: reversible accumulation factors and irreversible accumulation factors, which are different in the process of the development of business resources. Such as human re- 
Table1. Combination of industry factors (made by Jiang Xinxi)

\begin{tabular}{|c|c|c|c|c|c|}
\hline $\begin{array}{l}\text { COMBI } \\
\text { Serià } \\
\text { number }\end{array}$ & Industry structure & Industry scale & Industry quality & Industry Culture & Industry benefit \\
\hline 1 & $\begin{array}{l}\text { Human resource-intensive } \\
\text { type }\end{array}$ & $\begin{array}{l}\text { Demand for consump- } \\
\text { tion information }\end{array}$ & Stage of formation & $\begin{array}{l}\text { Institution } \\
\text { culture }\end{array}$ & $\begin{array}{l}\text { Welfare } \\
\text { of population }\end{array}$ \\
\hline 2 & Finance-intensive type & $\begin{array}{l}\text { Demand for means of } \\
\text { production }\end{array}$ & $\begin{array}{l}\text { Stage of develop- } \\
\text { ment }\end{array}$ & $\begin{array}{l}\text { Management } \\
\text { culture }\end{array}$ & $\begin{array}{l}\text { Regeneration of } \\
\text { business resources }\end{array}$ \\
\hline 3 & High equipment rate type & Demand for service & Stage of stability & $\begin{array}{l}\text { Business philoso- } \\
\text { phy }\end{array}$ & $\begin{array}{l}\text { Contribution to } \\
\text { environment }\end{array}$ \\
\hline 4 & $\begin{array}{l}\text { Information- dependence } \\
\text { type }\end{array}$ & Frequency of demand & Stage of recession & Popularized trend & Culture integration \\
\hline 5 & Location-dependence type & Density of Demand & Stage of integration & Personalized trend & $\begin{array}{l}\text { Industry integra- } \\
\text { tion }\end{array}$ \\
\hline 6 & $\begin{array}{l}\text { Natural resources- de- } \\
\text { pendence type }\end{array}$ & Environmental demand & Stage of adjustment & Harmonized trend & $\begin{array}{l}\text { Knowledge Inte- } \\
\text { gration }\end{array}$ \\
\hline
\end{tabular}

sources---the accumulation of knowledge and skills is irreversible, and payment depends on efficiency; information resources---the asymmetry and the timeliness, the dual character which lead knowledge and skills to appreciation or depreciation; relation resources---competition and cooperation are connected with relation, which is decided by not only material interests but also culture; time resources---it is an important characteristic of the natural cycle, time is capital as well as environment. From the accumulation of point of view, the structure selection of core industry is to choose the combination between reversible accumulation resources(such as finance, equipment, natural resources) and irreversible accumulation resources(such as knowledge and skills, information, relationships, time) to produce comprehensive- effective products and services, then realize the renewal of business resources.

\subsection{The scale selection of core industry}

The scale of core industry is selected according to the appropriate demands of society, economy and culture, and the principle of sustainable development. The demand of means of production in the industrial economy is the demand for self-development of industry, but it also can boost consumer demand, so reserving strategic means of production, in fact, is the basic method of stimulating consumption and promoting domestic demand. Taking advantage of the strength of information resources, relationship resources and space (location) resources, to promote the integration of technology resources (human resources), finance resources into production equipment to spur production and consumption, and putting forth effort to improve the circumstance of production and consumption, is effective approach of enlarging the scale of core industry. Moderate demand is the fundamental basis for moderate scale, but "moderate" itself is a "flexible variation range". Therefore, the scale selection of core industry should be based on the characteristic of main business resources and developmental stage of social economy. That is to say, we select the top of "flexible variation range" when strategic resources is relatively abundant and socio-economic development is at a high stage, and select the bottom when strategic resources is relatively insufficient and socio-economic development is at a low stage. In addition, the coordination between domestic demand and external demand is also an important factor in scale selection. Comparative advantage theory in the international economics strongly supports the method that expanding the scale of industrial sectors which have relatively high labor productivity and comparative advantage to meet the needs of international division of labor and external demand; However, when the international situation is turbulent, or the culture of innovation is prosperous, or domestic people's livelihood demand is strong, the method that expanding the scale of the industrial sectors with traditional influence is supported to stabilize the situation and meet domestic demand.

\subsection{The quality selection of core industry}

The appropriate operating time and operating cycle of core industry is chosen according to industrial sustainability and innate lifecycle laws. The preparation process of core industry is always accompanied by the dynamic mechanism of "market pulling" or "science and technology prompting". While the official formation of core industry depends on the technical group associated with the core technology whether can support the industry constantly. Generally the lifecycle of core industry has to go through the stages of (preparation) formation, development, stability, recession, integration, and adjustment (although the boundary of each stage is not obvious). The vitality in each stage is different, from the development economics point of view, shorting the period of preparation, extending the period of stability, delaying the period of recession, and ultimately promoting integration and adjustment positively is what should be done in industry design. We need to pay attention to the fact that the innovation process of technical group and the process of industry growth are in the same direction. But during 
the recession period, only by technological innovation might be able to delay the process of entering into recession, yet can't change the direction of the industrial life cycle. The development of industry is accompanied by cultural development. Cultural change will result in cultural integration of intra-industry or inter-industry, while cultural integration will lead to technology integration inevitably. That is because technology is the core competence of human resources in industry operation, and culture influences people's values (including technical view), then technology integration induces industry integration and finally changes core industry.

\subsection{The culture selection of core industry}

The choice of institution culture, management culture, and business philosophy should be based on the level of cultural education and the real situation of industrial population in the industrial area. Institution culture decides the developmental pattern of industry culture, management culture influences the effectiveness of industry culture, and business philosophy coordinates the various values between internal and external industry. History, politics, religion, legal system, geography, and technological progress have an impact on the choice of industry culture. The factor of cultural transmission and educational promotion can't be ignored in the selection of industry culture. In fact, regional industrial characteristic in most cases are induced by the regional cultural feature, and the three main economic subjects (government, enterprise, family) are also the main medium of regional culture. So the culture of core industry is also influenced by regional cultural feature, and resonating through the culture of regional industrial population can produce higher added value, and such added value can further the transmission of culture (for example, the ceramic industry culture in Jingdezhen area has indivisible relation with the culture and history of Jingdezhen). On the other hand, cultural trend (popularization, individuation, and harmonization) has a profound impact on consumption behavior. Thus it leads industrial market to be subdivided, and then influences the diversity of management culture, and establishes the connecting link between producers' philosophic thinking and consumers'.

\subsection{The benefit selection of core industry}

The direction of industrial development is chosen according to the basic principle of sustainable development. Industrial benefit is usually expressed as the aggregate of population welfare, regeneration of business resources, environmental contribution, cultural integration, industrial integration, and knowledge integration. The objective of the core industry is not only the social, economic and ecological benefits which come from the natural resources merely, but also we should take more attention at the return of human industry to nature such as environmental contribution and regeneration of business resources, furthermore, breaking cultural barriers in the process of industrial development to improve spiritual and cultural level of industrial population.

\section{SUMMARY}

It is important to figure out the basic content of industry factors in industry route design, and each factor has its benchmark and key point should not be ignored. Then the choice of core industry plays a decisive role in industry route design. Proper selection of core industry will determine all the economic development of industrial area and the rationalization of industry structure, and also induce an interrelated and complementary industrial cluster. In order to make a reasonable decision, the structure, scale, quality, culture and benefit of core industry must be taken into account.

\section{REFERENCES}

[1] Xinxi Jiang, Minwen He. 2015. A study on the establishment and development status of sub-business zone at chinese university economy. Proceedings of 2015 International Conference on Modern Economic Technology and Management, Asian Academic Press, pp.3-7.

[2] Xinxi Jiang, Wei Zhang. 2015. A study on the selection principle of industrial clusters based on industrial integrated design case study of forestry. Proceedings of 2015 International Conference on Modern Economic Technology and Management, Asian Academic Press.

[3] Xinxi Jiang, Wei Zhang. 2015. Preliminary studies on technique route design in forestry economy. Proceedings of 2015 International Conference on Modern Economic Technology and Management, Asian Academic Press, pp.67-72

[4] Heping Deng, Xinxi Jiang. 2006. Geological New Material. Human Science Press, pp.206-208.

[5] Xinxi Jiang, Hao Cheng. 2009. An approach to knowledge economics of universities. Journal of Jiangxi Normal University (Social Sciences), 04: 116-122.

[6] Xinxi Jiang. 2009. An Exploration of the Road to Form and Develop the Derivative Economic Circle Based on University Operation. Journal of Jiangxi Normal University (Social Sciences), 04: 116-122. 